\title{
Prevalence of Patent Foramen Ovale in the Japanese Population - Autopsy Study -
}

Junko Kuramoto, MD; Akio Kawamura, MD; Tomohisa Dembo, MD; Tokuhiro Kimura, MD; Keiichi Fukuda, MD; Yasunori Okada, MD

\begin{abstract}
Background: Patent foramen ovale (PFO) can cause ischemic stroke because of paradoxical embolism. Autopsy studies have shown that the prevalence of PFO is $25 \%$ in whites or blacks. However, there is a paucity of data on the prevalence of PFO in Asians. The aim of this study was to clarify the prevalence of PFO in the Japanese population.
\end{abstract}

Methods and Results: We reviewed 52,717 autopsy reports, which were collected and edited by the Japanese Society of Pathology from 2009 to 2012. Next, we inspected consecutive 103 formalin-fixed specimens that had already been examined by certified pathologists from 2009 to 2013 to find PFO and atrial septal aneurysm (ASA). ASA was defined as $\geq 10 \mathrm{~mm}$ protrusion of the septum into the left or the right atrium. In the database of the Japanese Society of Pathology, the incidence of PFO was $0.08 \%(43 / 52,717)$. Inspection of heart specimens disclosed that the prevalence of PFO was 13.6\% (14/103). None of the PFO cases was reported at the original autopsy. PFO was more frequently found in the subjects with ASA (50\%) than in those without ASA (9.7\%) $(P=0.004)$.

Conclusions: PFO is under-reported in autopsy reports. Re-evaluation of heart specimens disclosed that the prevalence of PFO was 13.6\%. The prevalence was lower than reported in the past. (Circ J 2015; 79: 2038-2042)

Key Words: Atrial septal aneurysm; Cryptogenic stroke; Ethnicity; Patent foramen ovale

$\mathbf{F}$ oramen ovale is an important cardiac structure for the fetal circulation between the right and left atria to provide oxygen-rich maternal blood to the fetal brain. In most cases it closes shortly after birth, but there are reports that it may still open in approximately $25 \%$ of adults. ${ }^{1}$ The condition is called patent foramen ovale (PFO). Recently, PFO has been the focus of attention because it can be associated with increased risk of stroke. ${ }^{2}$ Most PFO are benign and do no harm, but some PFO can open widely and enable thrombi to pass from the venous to arterial circulation. In addition to the embolic stroke, PFO has been linked to several other conditions, including migraine headache with aura, platypnea-orthodeoxia syndrome, decompression illness of divers, and sleep apnea. ${ }^{3}$

\section{Editorial $p 1904$}

Autopsy studies have shown that the prevalence of PFO is approximately $25 \%$ in whites or blacks. ${ }^{1}$ However, there is a paucity of data on the Asian population. The aim of this study was to clarify the prevalence of PFO in the Japanese population from nationwide autopsy data and autopsy specimens of hearts.

\section{Methods}

First, we reviewed 52,717 autopsy cases to find PFO in the Annual Report edited by the Japanese Society of Pathology from 2009 to 2012. The Annual comprises nationwide data gathered from over 800 hospitals in Japan, where certified pathologists performed all the autopsies. The data include age, sex, primary disease related to the death, and autopsy findings. ${ }^{4}$

Then, we inspected consecutive 109 autopsy formalin-fixed and preserved heart specimens, which were already examined by certified pathologists from November 2009 to October

Received February 20, 2015; revised manuscript received May 11, 2015; accepted May 13, 2015; released online June 18, 2015 Time for primary review: 26 days

Department of Pathology (J.K., Y.O.), Department of Cardiovascular Medicine (A.K., K.F.), Keio University School of Medicine, Tokyo; Department of Cardiovascular Medicine, National Defense Medical College, Tokorozawa (A.K.); Department of Internal Medicine and Neurology, Kyorin University School of Medicine, Mitaka (T.D.); and Department of Pathology, Yamaguchi University Graduate School of Medicine, Ube (T.K.), Japan

Mailing address: Akio Kawamura, MD, PhD, Department of Cardiovascular Medicine, National Defense Medical College, 3-2 Namiki, Tokorozawa 359-0042, Japan. E-mail: kawamra@cpnet.med.keio.ac.jp

ISSN-1346-9843 doi:10.1253/circj.CJ-15-0197

All rights are reserved to the Japanese Circulation Society. For permissions, please e-mail: cj@j-circ.or.jp 
2013. Of the 109 hearts, 6 were excluded because the specimens were damaged by the search for the heart's conduction system. Finally, 103 hearts were re-examined for the presence of PFO and atrial septal aneurysm (ASA). The autopsy reports and clinical backgrounds of the subjects were reviewed using medical records. Two certified pathologists and a cardiologist (J.K., T.K., A.K.) inspected the heart specimens for the presence of PFO and ASA without interobserver variations. ASA was defined as $\geq 10 \mathrm{~mm}$ protrusion of the septum into the left or right atrium. The diameter and tunnel length of PFO were measured. The prevalence of PFO and ASA was compared among different age groups $(\leq 59,60-79$ and $\geq 80)$. The institutional review board of Keio University School of Medicine approved the protocol (approval no. 20140126).

\section{Statistical Analysis}

We present the quantitative data as mean value $\pm \mathrm{SD}$, and qualitative data as frequencies. We compared continuous variables using paired Student's t-test, and categorical variables by chi-square test or Fisher's exact test. All probability values are two-tailed and $\mathrm{P}<0.05$ was considered statistically significant. Statistical analysis was performed with Stat View (Stat View 5.0, Abacus Concepts Inc, Calabasus, CA, USA).

\section{Results}

In the Annual, the reported incidence of PFO was $0.08 \%$ $(43 / 52,717)$. Of the 43 PFO cases, 30 patients were less than

\begin{tabular}{|lc|}
\hline \multicolumn{2}{|c|}{$\begin{array}{c}\text { Table 1. } \\
\text { Examined for PFO and ASA } \\
\mathrm{n}\end{array}$} \\
$\mathrm{Age}$, years & 103 \\
$\mathrm{Age} \geq 60$ years & $69(17-90)$ \\
Male & $74(72)$ \\
Cause of death & $72(70)$ \\
Malignancy & \\
Liver failure & $49(48)$ \\
Cardiovascular & $17(17)$ \\
Infection & $14(14)$ \\
Collagen disease & $11(11)$ \\
Other & $3(3)$ \\
\hline
\end{tabular}

ASA, atrial septal aneurysm; PFO, patent foramen ovale.

1 year old. The incidence of PFO cases older than 1 year old was $0.02 \%(13 / 52,717)$. In 1 case, paradoxical embolism because of PFO was reported.

Characteristics of the study population are shown in Table 1. All were Asian. None of the cases of PFO or ASA was diagnosed before death. The prevalence of PFO and ASA was $13.6 \%(14 / 103)$ and $9.7 \%(10 / 103)$, respectively. PFO is more likely to coexist with ASA (Figures 1,2). None of the cases of PFO and ASA was discovered or reported at the original

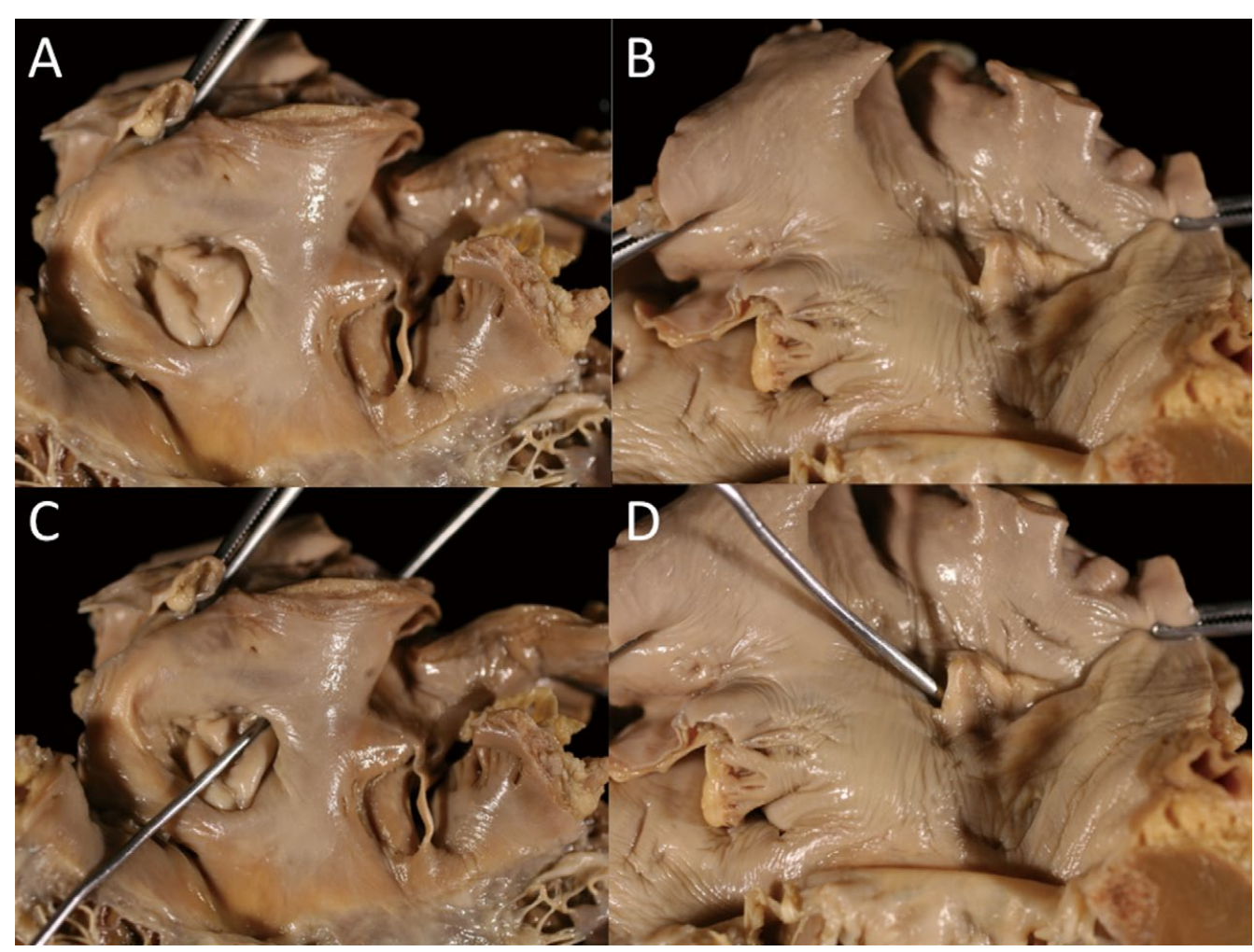

Figure 1. Gross anatomy of patent foramen ovale (PFO) and atrial septal aneurysm (ASA). (A) View from the right atrium showing ASA. (B) View from the left atrium (same subject as in A). (C) View from the right atrium showing coexistence of ASA and PFO. A probe is inserted through the PFO. (D) View from the left atrium with the probe inserted. 


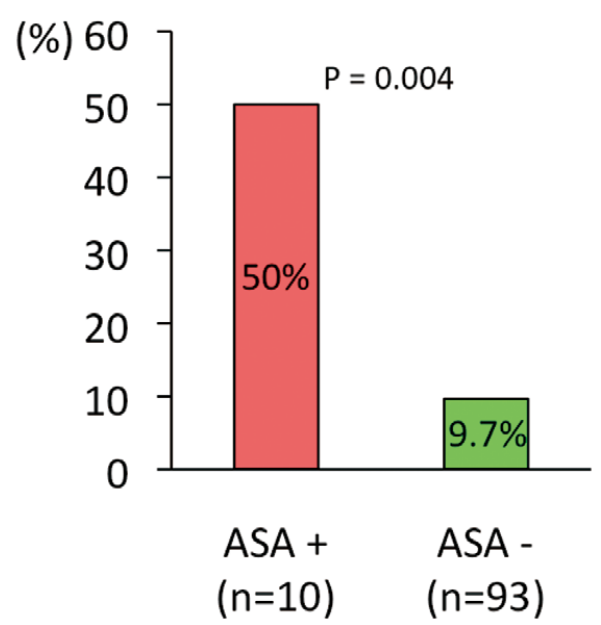

Figure 2. Prevalence of patent foramen ovale (PFO) in subjects with and without atrial septal aneurysm (ASA). autopsy. The prevalence of PFO did not differ among age groups $(\mathrm{P}=0.2367)$, whereas ASA was more frequently found in the subjects older than 80 years old $(\mathrm{P}=0.0039)$ (Table 2). The diameter of PFO ranged from 1 to $10 \mathrm{~mm}$ (mean $5.0 \mathrm{~mm}$ ) and was larger on the left atrial side than on the right atrial side $(5.9 \mathrm{~mm}$ vs. $4.3 \mathrm{~mm}, \mathrm{P}<0.005)$. The mean tunnel length was $4.2 \mathrm{~mm}(2-11 \mathrm{~mm})$. Most of the PFO had a flap-like shape, but the pinhole type was found in 1 case (Figure 3). There was no thrombus formation related to the PFO or ASA.

\section{Discussion}

The main findings of this study were that PFO and ASA are under-reported, and that the prevalence of PFO in both the nationwide database and the autopsy specimens was lower than reported in the past.

PFO has been generally regarded as a benign condition and seen in approximately $25 \%$ of the general population. Recently, however, the association of PFO with several diseases has been recognized, including paradoxical embolism, migraine headache with aura, platypnea-orthodeoxia syndrome, decom-

\begin{tabular}{|lcccc|}
\hline \multicolumn{4}{|l|}{ Table 2. Prevalence of PFO and ASA According to Age in Japanese Autopsy Series } & \\
$\mathrm{n}$ & $\mathbf{5} 5 \mathbf{9 0}$ & $\mathbf{6 0 - 7 9}$ & $\mathbf{8 0 0}$ & P value \\
PFO, $n(\%)$ & 29 & 58 & 16 & \\
ASA, $n(\%)$ & $2(7.0)$ & $8(13.8)$ & $4(25.0)$ & 0.2 \\
\hline
\end{tabular}

Abbreviations as in Table 1.

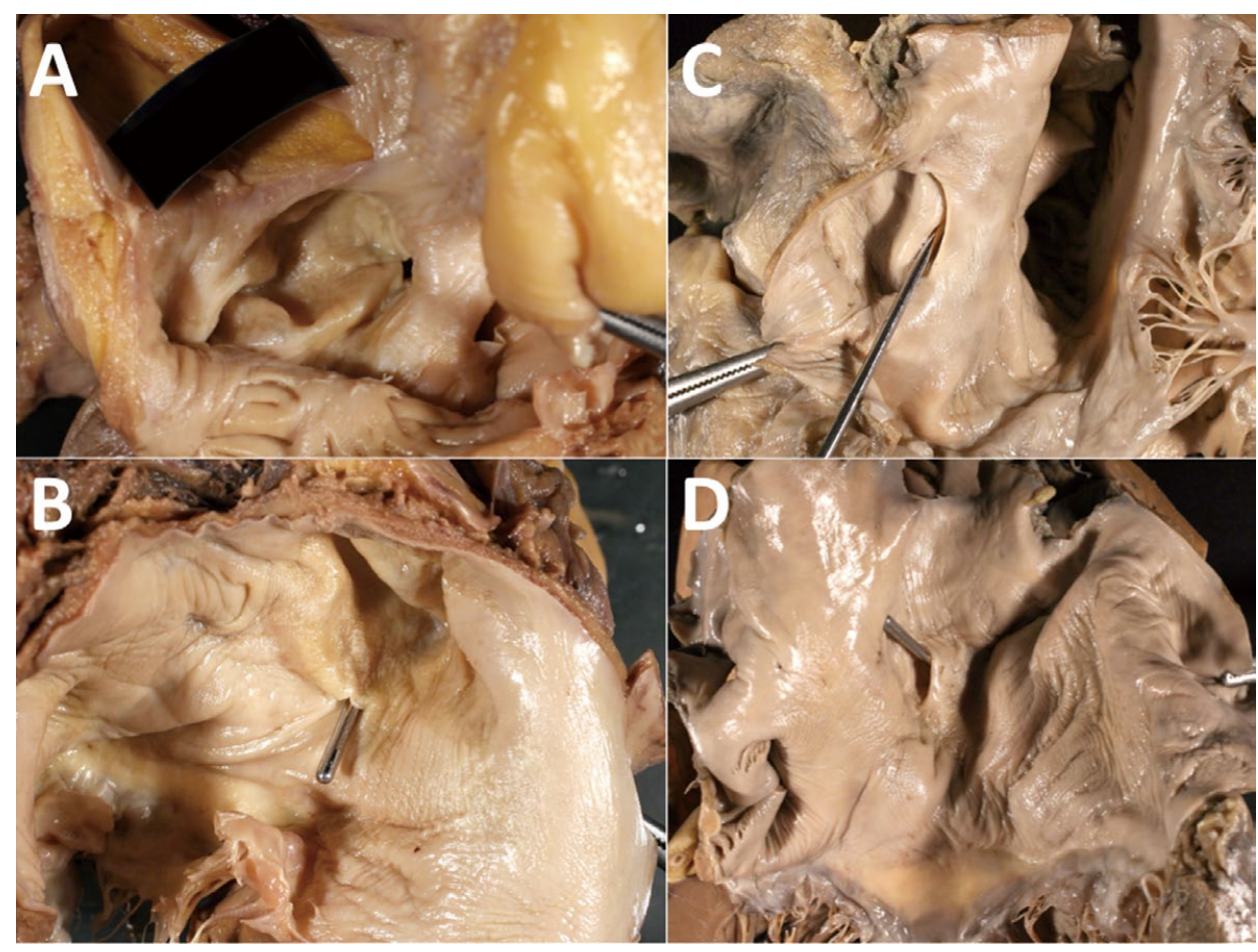

Figure 3. Gross anatomy of patent foramen ovale (PFO). (A) View from the right atrium showing a pinhole-type PFO. (B) View from the left atrium (same subject as in A). (C) View from the right atrium showing a typical flap-like PFO. (D) View from the left atrium (same subject as in $\mathbf{C}$ ). 


\begin{tabular}{|c|c|c|c|c|}
\hline Year & Authors & No. of hearts & Prevalence of PFO (\%) & Origin \\
\hline 1897 & Parsons and Keith ${ }^{13}$ & 399 & 26 & London, UK \\
\hline 1900 & Fawcett and Blachford ${ }^{14}$ & 306 & 32 & Bristol, UK \\
\hline 1930 & Thompson and Evans ${ }^{15}$ & 977 & 27 & London, UK \\
\hline 1934 & Seib ${ }^{16}$ & 500 & 17 & Minnesota, USA \\
\hline 1948 & Wright et al ${ }^{17}$ & 492 & 23 & Illinois, USA \\
\hline 1972 & Schroeckenstein et al ${ }^{18}$ & 144 & 35 & Minnesota, USA \\
\hline 1979 & Sweeney and Rosenquist ${ }^{19}$ & 64 & 31 & Nebraska, USA \\
\hline 1984 & Hagen et al ${ }^{1}$ & 965 & 27 & Minnesota, USA \\
\hline 1994 & Penther ${ }^{20}$ & 500 & 15 & Brest, France \\
\hline Total & & 4,347 & 25 & \\
\hline
\end{tabular}

Abbreviation as in Table 1.

\begin{tabular}{|c|c|c|c|c|}
\hline Year & Authors & No. of hearts & Prevalence of PFO (\%) & Origin \\
\hline 1897 & Parsons and Keith ${ }^{13}$ & 139 & 28 & London, UK \\
\hline 1900 & Fawcett and Blachford ${ }^{14}$ & 300 & 31 & Bristol, UK \\
\hline 1934 & Seib $^{16}$ & 500 & 17 & Minnesota, USA \\
\hline 1979 & Sweeney and Rosenquist ${ }^{19}$ & 64 & 31 & Nebraska, USA \\
\hline 1994 & Penther 20 & 500 & 15 & Brest, France \\
\hline Total & & 1,503 & 21 & \\
\hline
\end{tabular}

Abbreviation as in Table 1.

pression illness of divers, and sleep apnea. ${ }^{2}$ Of these conditions, the most devastating complications are paradoxical embolism leading to stroke, myocardial infarction, or infarct of other vital organs. Thus, for prevention of paradoxical embolism, transcatheter PFO closure has been performed worldwide. ${ }^{5-10}$ Our study indicates that paradoxical embolism is a rare event for most Japanese subjects with PFO. In the autopsy cases, there were no paradoxical emboli and only 1 case in the nationwide database was identified as paradoxical embolism because of PFO. However, PFO is clearly under-reported, which means that clinicians and pathologists have a low awareness of paradoxical embolism caused by this structure.

For patients with stroke of unknown etiology, a transesophageal cardiac ultrasound study showed that the frequency of PFO was similar among whites $(34 \%)$, blacks $(31 \%)$, and Hispanics (37\%). ${ }^{11}$ However, their subjects did not include Asians. Another study using transthoracic cardiac ultrasound disclosed a lower prevalence of PFO in Indo-Asians (2\%) compared with whites $(2.4 \%)$ or blacks $(7 \%)$, but the overall prevalence of PFO was lower than expected in their study (2\%), possibly because of the lower diagnostic sensitivity of transthoracic cardiac ultrasound. ${ }^{12}$ Autopsy is a most precise method for detecting PFO and its prevalence in past autopsy studies was $24.6 \%$ overall (Table 3).1,13-20 Most of those reports included specimens from infants. If they are limited to adults, ${ }^{13,14,16,19,20}$ the prevalence is lower (20.6\%), possibly because some PFO close after 1 year of age (Table 4). In the Japanese nationwide database, PFO was reported in only $0.08 \%$. In the hospital autopsy cases, PFO was not identified in the original reports. Unless special attention is paid, PFO can be easily overlooked. Re-inspection revealed that the prevalence of PFO was $13.6 \%$, the lowest among the autopsy reports (Figure 4).

In our study, PFO was strongly associated with ASA: PFO

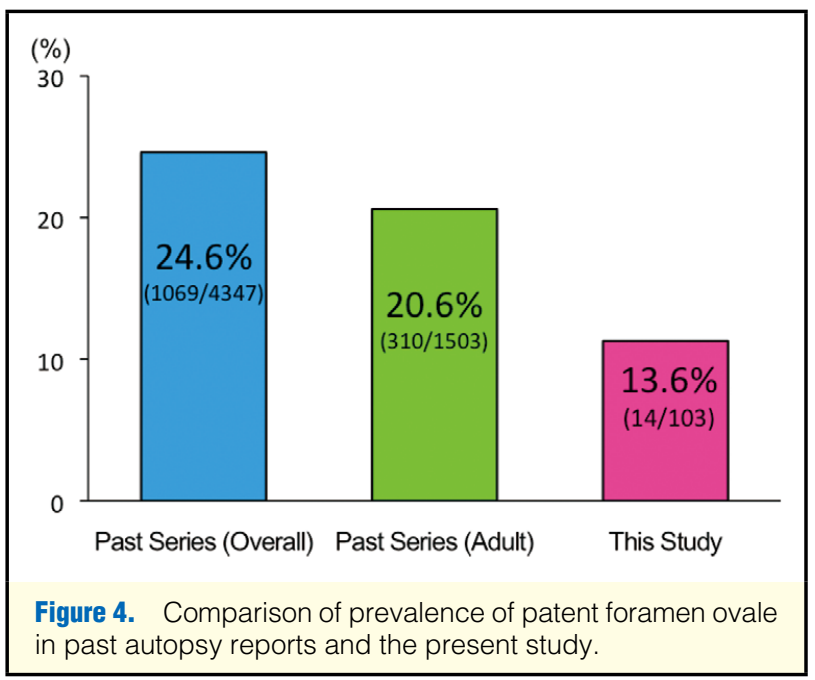

was found in $50 \%$ of patients with ASA, but in $9.7 \%$ of patients without ASA, which is in line with the literature. The odds of PFO are 4.6-fold greater with ASA than without ASA. ${ }^{21}$ A small PFO may be missed by transthoracic cardiac ultrasound, but ASA is easier to find. If we encounter ASA in patients with cryptogenic stroke, PFO should be thoroughly searched for. Because PFO is an important cause of paradoxical embolic stroke, especially in the young population, special attention should be paid at cardiac ultrasound as well as autopsy.

\section{Study Limitations}

An important limitation of this study is that it was an autopsy 
study. It may not represent the general population. Second, the number of re-inspected cases was small and the age of the population was relatively high compared with previous studies. Depending on the age of population, the prevalence could be different. Finally, we did not make a direct comparison of the prevalence of PFO among different ethnic groups because our study included only an Asian population.

\section{Conclusions}

At autopsy, PFO was under-reported. In a re-evaluation of the Japanese autopsy hearts, we found PFO in $13.6 \%$, which was lower than reported in the past.

\section{References}

1. Hagen PT, Scholz DG, Edwards WD. Prevalence and size of patent foramen ovale during the first 10 decades of life: An autopsy study of 965 normal hearts. Mayo Clin Proc 1984; 59: 17-20.

2. Fisher M, McAllister M. Cardiological aspects of stroke prevention. Circ J 2015; 79: 271-277.

3. Calvert PA, Rana BS, Kydd AC, Shapiro LM. Patent foramen ovale: Anatomy, outcomes, and closure. Nat Rev Cardiol 2011; 8: 148 160.

4. The Japanese Society of Pathology. Annual of the pathological autopsy cases in Japan: 2009-2012. Tokyo: JSP, 2013; 52-55 (in Japanese)

5. Khairy P, O’Donnell CP, Landzberg MJ. Transcatheter closure versus medical therapy of patent foramen ovale and presumed paradoxical embolism. Ann Intern Med 2003; 139: 753-760.

6. Windecker S, Wahl A, Nedeltchev K, Arnold M, Schwerzmann M, Seiler C, et al. Comparison of medical treatment with percutaneous closure of patent foramen ovale in patients with cryptogenic stroke. J Am Coll Cardiol 2004; 44: 750-758.

7. Inglessis I, Elmariah S, Rengifo-Moreno PA, Margey R, O'Callaghan C, Cruz-Gonzalez I, et al. Long-term experience and outcomes with transcatheter closure of patent foramen ovale. J Am Coll Cardiol Interv 2013; 6: 1176-1183.

8. Lehmann R, Fichtlscherer S, Baldauf H, Schächinger V, AuchSchwelck W, Zeiher AM, et al. Ten years of experience with closure of persistent foramen ovale: Patient characteristics and outcomes. $J$ Cardiol 2014; 64: 113-116.

9. Musto C, Cifarelli A, Fiorilli R, De Felice F, Parma A, Nazzaro MS, et al. Comparison between the new Gore septal and Amplatzer devices for transcatheter closure of patent foramen ovale: Short- and mid-term clinical and echocardiographic outcomes. Circ J 2013; 77: $2922-2927$.

10. Zhang CJ, Huang YG, Huang XS, Huang T, Huang WH, Shen JJ. Transcatheter closure of patent foramen ovale in Chinese patients with paradoxical embolism: Immediate results and long-term followup. Circ J 2011; 75: 1867-1871.

11. Rodriguez CJ, Homma S, Sacco RL, Di Tullio MR, Sciacca RR, Mohr JP; for PICCS investigators. Race-ethnic differences in patent foramen ovale, atrial septal aneurysm, and right atrial anatomy among ischemic stroke patients. Stroke 2003; 34: 2097-2102.

12. Salmasi AM, Salmasi H, Rawlins S, Baakil M, Dancy M. Atrial septal aneurysm and patent foramen ovale are less prevalent in the Indo-Asian than in the Caucasian of Afro-Caribbean population. Angiology 2010; 61: 205-210.

13. Parsons FG, Keith A. Seventh report of the Committee of Collective Investigation of the Anatomical Society of Great Britain and Ireland, for the year 1896-1897. J Anat Physiol 1897; 32: 164-186.

14. Fawcett E, Blachford JV. The frequency of an opening between the right and left auricles at the seat of the fetal foramen ovale. J Anat Physiol 1900; 35: 67-70.

15. Thompson T, Evans W. Paradoxical embolism. Q J Med 1930; 23: $135-152$.

16. Seib GA. Incidence of the patent foramen ovale cordis in adult American whites and American negroes. Am J Anat 1934; 55: 511 525 .

17. Wright RR, Anson BJ, Cleveland $\mathrm{HC}$. The vestigial valves and the interatrial foramen ovale of the adult human heart. Anat Rec 1948; 100: $331-335$.

18. Schroeckenstein RF, Wasenda GJ, Edwards JE. Valvular competent patent foramen ovale in adults. Minn Med 1972; 55: 11-13.

19. Sweeney LJ, Rosenquist GC. The normal anatomy of the atrial septum in the human heart. Am Heart J 1979; 98: 194-199.

20. Penthr P. Patent foramen ovale: An anatomical study: Apropos of 500 consecutive autopsies. Arch Mal Coeur Vaiss 1994; 87: 15-21.

21. Agmon Y, Khandheria BK, Meissner I, Gentile F, Whisnant JP, Sicks JD, et al. Frequency of atrial septal aneurysms in patients with cerebral ischemic events. Circulation 1999; 99: 1942-1944. 